\title{
TEORIA DA ATIVIDADE E MODELOS DE LEITURA EM LIVROS DIDÁTICOS DE PORTUGUÊS - L2
}

\author{
Cândida Martins Pinto \\ Candidamp@yahoo.com.br \\ Marcos Gustavo Richter \\ mrichter@cal.ufsm.br
}

\begin{abstract}
Nowadays, considering the process of a foreign language or second language acquisition, a big importance is given to the previous knowledge of the learner: top-down model. As the same rule, bottom-up model, involving formal and grammatical aspects, has its relevance in a second stage of the learning. A mature learner is that who is able to link these two models during the reading, using, thus, the interactive model. Considering this, this study aims to, in a first stage, discuss relevant questions for the use of the three models in language classes in general and in Portuguese for foreigner classes in particular, as well as the importance of them for a good reading. In a second stage, a Portuguese for foreigners textbook will be analyzed, according to Activity Theory, in order to verify when the models appear in reading tasks.
\end{abstract}

\section{INTRODUÇÃO}

Pesquisas sobre leitura têm ocorrido desde o ano de 1979 quando Emile Javal publicou seu primeiro artigo sobre o movimento dos olhos durante a leitura (Samuels e Kamil, 1988). Desde então muitos pesquisadores têm procurado responder como ocorre o inteiro processo de ler desde a fixação do olho até a compreensão total do texto.

A leitura envolve linguagem, memória, pensamento e inteligência, bem como percepção, que desencadeiam operações que auxiliam a compreensão da linguagem. Assim, sendo o processo de ler complexo, diversos autores (Gough, 1976; LaBerge e Samuels, 1976; Goodman, 1967; Rumelhart, 1977, 1984, descritos em Samuels e Kamil, op. cit) discutiram teorias, algumas delas já rediscutidas, sobre o processo em si e modelos para esse processo.

Teoricamente, há três modelos de leitura, embasados por preceitos cognitivos: o modelo descendente (ou top-down), defendido por Goodman (1969, 1970, $1975,1988)$, que processa predições progressivamente sobre pequenas unidades do texto, contrastando com o conhecimento prévio do leitor; o modelo ascendente (também chamado bottom-up), defendido por Gough (1972), que processa a leitura a partir de uma seqüência linear - das letras para sons, para palavras, para sentenças e finalmente para significado; e o modelo interativo, defendido por Rumelhart (1977, 1985), que argumenta em prol da ocorrência dos dois processos bottom-up e top-down simultaneamente ou alternadamente. 
Dessa forma, o presente estudo tem por objetivo, primeiramente, discutir questões relevantes para auxiliar os alunos a compreender um texto no ato da leitura. Para tanto, discuto a importância dos modelos top-down, bottom-up e interativo para o ensino de línguas. Em seguida, analiso um livro didático de português para estrangeiros, de acordo com a Teoria da Atividade de Leontiev (1978), e verifico a recorrência dos modelos em atividades de leitura.

\section{O MODELO DESCENDENTE}

Durante a leitura, leitores usam seu conhecimento prévio para interpretar o texto e criar expectativas plausíveis sobre o que eles irão ler. Esse modelo de leitura, desenvolvido por Goodman (1969, 1970, 1975, 1988), tem sido referido como top-down ou modelo descendente. Para Goodman (1988, p. 12):

a leitura é um processo receptivo da linguagem. É um processo psicolingüístico no qual começa com uma representação da superfície lingüística codificada por um escritor e termina com o significado que o leitor constrói. Há, dessa maneira, uma interação essencial entre linguagem e pensamento na leitura. $O$ escritor codifica pensamento em linguagem e o leitor codifica linguagem em pensamento ${ }^{2}$.

Segundo o referido autor (1984), o significado não é uma característica dos textos; textos, construídos por escritores, são compreendidos por leitores. O significado, por sua vez, está entre autor e leitor, sendo representado pelo escritor no texto e construído do texto pelo leitor.

O modelo de leitura top-down, desenvolvido a partir de observação da leitura oral, foi também chamado de "jogo psicolingüístico de adivinhação", já que o leitor faz constantes adivinhações sobre o que virá na leitura de acordo com seu conhecimento sobre o assunto, confirmando hipóteses ou formando novas. Dessa forma, Goodman (1988) propôs cinco processos que são empregados pelos leitores durante a leitura. O cérebro é o órgão processador das informações; ele decide qual tarefa deve ser executada, qual informação está disponível, quais estratégias devem ser empregadas, onde buscar informação. O cérebro procura maximizar informações requeridas e minimizar esforço e energia usados para adquiri-las. Os cinco processos são (idem, p. 16):

1. Reconhecimento-iniciação: o cérebro deve reconhecer uma manifestação gráfica no campo visual como linguagem escrita e iniciar a leitura.

2. Predição: O cérebro está sempre antecipando e predizendo enquanto procura ordem e significância para o input sensório.

3. Confirmação: Se o cérebro faz predições, deve também procurar verificálas. Então, ele monitora para confirmar ou não confirmar com input subseqüente o que é esperado.

4. Correção: O cérebro reprocessa quando encontra inconsistências ou suas predições não são confirmadas.

5. Término: O cérebro termina a leitura quando a tarefa de ler e completada, mas o término pode ocorrer por outras razões: a tarefa não é produtiva; pouco significado está sendo construído, ou o significado já é conhecido, ou a história não é interessante, ou o leitor a considera inapropriada para o propósito particular ${ }^{3}$. 
Ao fazer essa leitura cíclica entre reconhecimento, predição, confirmação, correção e após, terminar a leitura, o leitor ativa esquemas, que são derivados do conhecimento lingüístico e do seu conhecimento de mundo. Segundo Carrell (1988, p. 244):

a Teoria do Esquema (Bartlett 1932; Rumelhart e Ortony 1977; Rumelhart 1980 , discutido mais adiante) mostra que quanto mais conhecimento prévio o leitor tiver do assunto do texto, melhor o leitor compreendê-lo-á. A implicação disso é que os aparentes problemas de leitura de alguns estudantes podem ser problemas de conhecimento prévio insuficiente ${ }^{4}$.

Como exemplo, a autora cita que uma das mais óbvias razões da falha de um esquema para o leitor de uma segunda língua é o esquema especifico de uma dada cultura, a qual não faz parte de conhecimento de mundo do leitor. Eis a importância do conhecimento prévio para o ensino de línguas.

No intuito de solucionar o problema de conhecimento prévio, Carrell (op. cit) sugere que o melhor método a ser usado para construir esse conhecimento é fazer uso de atividades de pré-leitura. Essas atividades podem ser: ver filmes, slides, peças de teatro, imagens, lembrar de experiências da vida real, fazer debates e discussões, fazer predições do texto, introduzir e discutir vocabulário relevante do texto, construir mapas semânticos.

Na próxima seção, discutiremos o modelo de leitura bottom-up, que apresenta a leitura partindo da compreensão do léxico até chegar ao texto como um todo.

\section{O MODELO ASCENDENTE}

Apesar de pesquisas prévias no campo de estudos de ensino de uma segunda língua apontarem para um ensino de leitura pautado no modelo top-down, atualmente muitos pesquisadores, dentre eles Carrell (1988) têm sentido a necessidade de enfatizar que uma leitura em segunda língua eficiente e efetiva requer ambos os processos top-down e bottom-up.

O modelo bottom-up, também chamado de ascendente, foi publicado em 1972 por Gough. Assume que todas as letras do campo visual devem ser consideradas individualmente pelo leitor para assinalar o significado de cada uma. Com essa publicação, o impacto da abordagem de processamento das informações para o estudo dos processos mentais é visto no campo da leitura ${ }^{5}$ (Samuels e Kamil, 1988, p. 24).

Paz, citando o criador do modelo, (2006, p. 79) explica o que ocorre durante a leitura:

A leitura começa com uma fixação dos olhos. Os olhos do leitor focalizam um ponto levemente recuado do começo da linha, e eles permanecem naquela fixação por alguns segundos. Então eles varrerão graus do ângulo visual em um movimento rápido dos olhos, e uma nova fixação começará. Excetuando as regressões e ignorando as varreduras de retorno, esta seqüência será repetida, contanto que a leitura continue. Quando a fixação inicial é alcançada, um modelo visual é refletido na retina. Isso estabelece 
em movimento uma seqüência intrincada de atividades no sistema visual, culminado na formação do ícone.

Dessa forma, o processamento bottom-up decodifica unidades lingüísticas individuais (por exemplo, fonemas, grafemas, palavras) e constrói significado textual das pequenas unidades para as maiores (das partes para o todo), ou seja, centra-se na habilidade de decodificar ou transformar em som o que é visto linearmente em um texto.

A grande contribuição desse modelo para o ensino de línguas está em exercícios que enfatizam habilidades gramaticais e o desenvolvimento do vocabulário, segundo diversos estudos descritos por Carrell (1988), tanto para leitores nativos quanto para os não-nativos. Um desses estudos, desenvolvidos por Cohen et al. mostrou que leitores não-nativos lêem mais localmente do que os nativos e, em conseqüência de não prestarem atenção aos elementos conjuntivos do texto, os não nativos têm problemas em sintetizar informações através das sentenças e dos parágrafos. Outros pesquisadores como Mackay (1979) e Cowan (1976) também têm similarmente argumentado que o reconhecimento de conjunções e de outros elementos lingüísticos que aparecem entre sentenças é crucial para o entendimento das informações do texto. Esses e outros estudos, então, enfatizam a necessidade de se trabalhar elementos locais do texto, incluindo instruções em elementos coesivos (substituição, elipses, conjunções, coesão lexical) e suas funções entre sentenças e parágrafos. Tais instruções, de acordo com Carrell (1988, p. 241), podem deixar os estudantes conscientes de quais idéias num texto são unificadas por esses elementos coesivos 6 .

Outra habilidade crucial de decodificação bottom-up é o desenvolvimento do vocabulário e o reconhecimento de palavras. Carrell (idem) também pontua que, ao contrário da visão tradicional do vocabulário, atualmente sabe-se que uma determinada palavra não tem uma noção fixa, esta dependerá do contexto e do conhecimento prévio do leitor, podendo, assim, assumir variados significados. Se o leitor não possui experiências prévias sobre determinada palavra empregada em determinado contexto, então, a compreensão do item lexical e da sentença como um todo será afetada. Para Carrell (1988, p. 242):

uma importante parte de ensinar conhecimento prévio é ensinar o vocabulário relacionado a ele, e, conversivamente, ensinar vocabulário pode significar ensinar novos conceitos, novo conhecimento. Conhecimento de vocabulário implica conhecimento de esquemas nos quais um conceito participa, conhecimento do sistema do qual a palavra participa, bem como qualquer palavra associada e conceitos.

A autora sugere que pré-atividades podem ser úteis também para o ensino do vocabulário, porém essas atividades devem enfatizar palavras-chave, escolhidas de acordo com o contexto semântico e o conhecimento prévio do aprendiz.

A seguir discutiremos o modelo de leitura interativo, que integra atividades topdown e bottom-up para o ensino de línguas.

\section{O MODELO INTERATIVO}


Rumelhart (1985) defende a idéia que o mais eficiente processamento de textos é o interativo, que combina os modelos top-down e bottom-up. Segundo Carrell (1988), a dependência de um modo de processamento e a negligência de outro constituem a causa das dificuldades de leitura para leitores de segunda língua. Um leitor maduro, dessa forma, usa os dois processamentos, mudando de um para o outro durante a leitura, enquanto que um leitor menos habilidoso tende a focar apenas um, produzindo prejuízos que afetam a compreensão do texto.

Para Rumelhart (idem), leitura é um processo perceptual e cognitivo de entender linguagem escrita. Começa com um movimento da retina e termina (quando bem-sucedido) com uma idéia definida sobre a intenção do autor com o texto. O autor ainda acrescenta que um leitor habilidoso deve ser capaz de fazer uso de informações sensórias, sintáticas, semânticas e pragmáticas para ter sucesso na atividade ${ }^{8}$ (idem, p. 722) de uma maneira não linear. Percebe-se, dessa forma, que o conceito de leitura vai ao encontro dos dois modelos.

Carrell e Eisterhold (1988), discutindo sobre o modelo interativo, assinalam que o papel do conhecimento prévio na compreensão da linguagem tem sido formalizado a partir da Teoria dos Esquemas. Afirmam (idem, p. 76) que o processo de interpretação é guiado pelo princípio que todo input é mapeado contra alguns esquemas existentes e que todos os aspectos daquele esquema devem ser compatíveis com a informação do input ${ }^{9}$. Esses princípios resultam em dois modelos de processamento de informações - top-down (do geral para 0 particular) e bottom-up (do particular para o geral).

O modelo interativo, de acordo com Eskey e Grabe (1988, p. 224), assume que:

habilidades de todos os níveis estão disponíveis interativamente para pro-
cessar e interpretar textos [...] Este modelo incorpora implicações de leitura
como um processo interativo - isto é, o uso de conhecimento prévio, ex-
pectativas, contexto, entre outros. Ao mesmo tempo, incorpora noções de
reconhecimento de característica rápida e acurada de letras e palavras, es-
tendendo a ativação de formas lexicais, e o conceito de automaticidade no
processamento dessas formas - isto é, um processamento que não de-
pende do contexto para o primeiro reconhecimento de unidades lingüísti-
cas ${ }^{10}$.

Para estudantes de línguas em geral e de segunda língua em particular, o uso de estratégias e habilidades bottom-up e top-down devem ser desenvolvidas conjuntamente, visto que ambas contribuem diretamente para o sucesso da compreensão do texto. Segundo Grabe (1988), há razões para se interessar no modelo interativo para o ensino de LE ou L2: $1^{\circ}$ ) há muitos estudos no campo de LE ou L2 que notam deficiências lingüísticas como fatores que desencorajam a leitura; $2^{\circ}$ ) pesquisadores têm notado a necessidade de vocabulário extensivo para a leitura; $3^{\circ}$ ) há necessidade de explicar maus leitores que fazem adivinhação excessivamente; $4^{\circ}$ ) evidências de pesquisas com língua materna indicam que bons leitores não são bons simplesmente porque são bons adivinhadores ou fazem melhor uso do contexto. 
Após as considerações feitas sobre os três modelos de leitura, passaremos a descrever a metodologia que embasa este estudo.

\section{METODOLOGIA}

O corpus do presente estudo é um livro didático do aluno (também chamado doravante LDA) de português para estrangeiros, da editora Pontes, e seu respectivo guia pedagógico do professor (GP). O LDA tem por objetivo desenvolver as habilidades de compreensão e de expressão oral e escrita do aluno estrangeiro nas normas culta e coloquial brasileiras. É constituído por 13 unidades - cada uma com uma temática - por exemplo: Unidade 1 - Minha família; Unidade 2 - No café da manhã; Unidade 3 - No escritório. As unidades são divididas em 6 seções: Motivação, Diálogos, Conteúdo Gramatical, Expansão Vocabular, Atividades e Leitura Suplementar. As atividades de leitura aparecem nas seções Atividades e Leitura Suplementar.

Para a análise do corpus, primeiramente, utilizarei os fundamentos da Teoria da Atividade, defendida por Leontiev (1978), para analisar quais são os sujeitos envolvidos, o objeto e as ferramentas utilizadas, bem como a atividade, as ações e a operação que embasam o contexto do livro didático.

Em um segundo momento, verifico a recorrência dos modelos top-down, bottom-up e interativo nas atividades de leitura presentes no LDA. Para tanto, analiso as quatro primeiras unidades do livro, já que apenas estas são detalhadas no GP. Nas demais, somente são destacadas as questões que possam apresentar certa dificuldade ${ }^{11}$.

Entretanto, antes de passarmos para a análise e discussão dos dados, faz-se necessária uma breve revisão da literatura sobre a Teoria da Atividade, desenvolvida por Leontiev (1977).

\subsection{TEORIA DA ATIVIDADE}

A partir da morte de Vygotsky em 1934, desenvolveu-se uma teoria, liderada por Leontiev, chamada Teoria da Atividade, que tenta analisar o desenvolvimento da consciência em cenário de atividade social prática (Daniels, 2003, p. 111). A ênfase recai nos impactos psicológicos da atividade organizada, e nas condições e sistemas sociais produzidos em e por tal atividade. Leontiev (1977) mostrou que essa análise deve ser formulada de acordo com três diferentes níveis: atividade, ação e operação.

A idéia de atividade, proposta por Leontiev (idem), baseia-se na concepção de - ser humano ser capaz de agir de maneira voluntária sobre o mundo para transformá-lo intencionalmente, buscando atingir determinados fins (Carelli, 2003, p. 35). Para tanto, Leontiev se pauta na concepção de que a atividade surge de determinados fins, que impulsionam motivos orientados para um objeto. E para que estes objetivos sejam atingidos, são requeridas ações (Libâneo, 
2004, p. 13). As operações, portanto, consistem no modo de execução de uma ação, são os meios necessários para o desenvolvimento de qualquer ação, determinada pela natureza da tarefa. É válido ressaltar que o mesmo objeto pode ser alcançado por diferentes operações e que a mesma operação pode realizar diferentes ações. Para Leontiev (citado por Libâneo, idem, p. 13), o que distingue uma atividade de outra é o objeto da atividade que confere à mesma determinada direção. O quadro abaixo ilustra esses níveis da atividade:

\begin{tabular}{|cc|}
\hline NÍVEL & ORIENTAÇÃO \\
Atividade & Motivo \\
$\underline{\imath}$ & $\underline{\uparrow}$ \\
Ação & Metas \\
$\underline{\uparrow}$ & $\underline{\uparrow}$ \\
Operação & Condição
\end{tabular}

Quadro 1: Níveis hierárquicos de uma atividade (Leontiev, 1977).

Daniels (2003, p. 116), citando Leontiev, explica atividade a partir do exemplo de aprender a dirigir um carro, que ilustra o movimento de um nível da estrutura de uma atividade para outro:

no início, toda operação, como mudar as marchas, é formada com uma ação subordinada especificamente a essa meta e tem sua própria base de orientação consciente. Em seguida, a ação é incluída em outra ação, por exemplo, mudar a velocidade do carro. Mudar as marchas torna-se um dos métodos para atingir a meta, a operação que efetua a variação da velocidade, e mudar as marchas cessa agora de ser realizada como um processo orientado para uma meta: sua meta não é isolada. Para a consciência do motorista, mudar as marchas em circunstâncias normais é como se não existisse. Ele faz algo mais: ele tira o carro de um lugar, sobe ladeiras íngremes, dirige o carro em alta velocidade, pára em determinado lugar etc. $\mathrm{Na}$ verdade, essa operação [de mudar de marchas] pode, como se sabe, ser totalmente retirada da atividade do motorista e executada automaticamente. Em geral, o destino da operação torna-se, mais cedo ou mais tarde, a função da máquina.

A Teoria da Atividade proposta por Leontiev pode ser considerada um desdobramento dos postulados básicos de Vygotsky, especialmente no que concerne ao conceito de mediação. A atividade humana, ou seja, a interação entre os sujeitos e seu ambiente, é mediada por artefatos (ou ferramentas). Esses artefatos modelam a maneira como as pessoas interagem com a realidade, transformando o funcionamento externo e o interno dos indivíduos.

As implicações metodológicas da teoria da atividade levam em conta, portanto, a análise dos níveis hierárquicos da atividade dentro de um determinado contexto, mediando os sujeitos envolvidos por determinados artefatos. Para Carelli (2003, p. 55), a atividade deve ser entendida como um sistema de atividades funcionais das interações socioculturais que constitui comportamento e produz aquele tipo de mudança denominado aprendizagem. 


\section{ANÁLISE E DISCUSSÃO DOS DADOS}

Esta seção está dividida em duas subseções: a primeira discute a relação entre a Teoria da Atividade e o contexto do livro didático do aluno, enquanto que a segunda traz uma descrição da recorrência dos modelos de leitura presentes nas atividades de leitura do LDA.

\subsection{O Contexto do Livro Didático}

Pinto e Richter (2006), em estudo preliminar, aplicaram a Teoria da Atividade ao contexto do livro didático, aqui considerado um gênero textual. Os autores chegaram à seguinte sistematização:

a) Primeiro Nível da Atividade - No intuito de estudar português como segunda língua, alunos estrangeiros se inserem em um contexto de aprendizagem mediado pelo livro didático. O motivo pelo qual o aluno se engaja na atividade é o desejo de aprender português. Essa atividade é orientada por um objeto (ou motivo), que induz o aluno a alguma transformação no seu conhecimento, tanto representativo quanto procedural. Assim, pode-se dizer que o objeto neste contexto, num primeiro momento, é o desempenho lingüístico e comunicativo do aluno e, num segundo momento, a aquisição do português como segunda língua, ou melhor, a consolidação do português como sistema lingüístico manifesto em termos de competência comunicativa.

b) Segundo Nível da Atividade - Como todo objeto ou motivo orienta e controla uma ação (ou encadeamento de ações), esta(s) organiza $(m)$ o trabalho pedagógico, que incide sobre o objeto, afetando-o a fim de alcançar um resultado, neste caso, um benefício acordado por professor e aluno - 0 incremento do desempenho lingüístico do aluno. De acordo com Leontiev (2001, p. 72), "para que uma ação surja, é necessário que seu objetivo (seu propósito direto) seja percebido em sua relação com o motivo da atividade". Assim, se o motivo do aluno é aprender a língua portuguesa (nível da atividade), as ações que ele realizará para atingir sua meta consistirão em exercícios, tarefas, leituras etc. que o ajudarão a obter a competência comunicativa desejada. Esses exercícios, inseridos (mediante seleção e organização criteriosa de textos e tarefas) pelo professor-designer num livro ou coleção didática, formam as várias etapas do processo (verdadeiros encadeamentos consistentes de ações, quando o curso é bem estruturado), as quais, orientadas ao motivo exposto inicialmente, deverão ser atingidas sucessivamente uma a uma para obter o resultado desejado.

c) Terceiro Nível da Atividade - O contexto de ensino em que professor e aluno se inserem permite que os mesmos desenvolvam determinados papéis. Se o papel do aluno é realizar ações, o do professor é gerenciar essas ações. Para tanto, o instrumento utilizado pelo professor é o livro didático, que o ajudará a implementar e controlar as ações lingüísticas do aluno (ações efetuadas sobre um input, que se modifica a um output) até que o aluno consiga gerenciálas sozinho. O que norteia o papel do professor e o papel do aluno e leva-os a convergirem (na didática bem-sucedida) é a busca por um resultado comum: o aprendizado da língua-alvo. As ações, desempenhadas pelo aluno e gerencia- 
das pelo professor, internalizam-se proceduralmente e são conduzidas de forma gradual ao automatismo (nível da operação), resultando a aquisição.

Tomemos um exemplo análogo ao proposto por Leontiev (2001): digamos que o aluno estrangeiro concebe o objetivo de decorar o vocabulário relevante de um texto para uma prova. A ação dele consistirá, então, em uma ativa memorização. Todavia, para conseguir atingir sua meta, o aluno poderá tomar vários caminhos. Em um caso, por exemplo, poderá escrever o vocabulário num caderno; em outra ocasião, poderá repeti-lo em voz alta. Em ambos os casos, a ação conduzida é a memorização, mas os meios para executá-la, ou seja, as operações implicadas, serão diferentes. As tarefas elaboradas pelo professor designer elicitam a predisposição ou coerção do aprendiz a efetuar preferencialmente esta ou aquela operação viável sobre um material lingüístico (ou semiótico), a fim de gerar uma relação input-output que consista em uma microhabilidade, no todo ou em parte, ou contribua para esta, de acordo com o que se sabe sobre aquisição.

A fluência a ser ganha nessas habilidades estará associada à conquista do automatismo; antes disso, o aluno as realiza de forma consciente, com lentidão e eventuais hesitações, etapa em que elas ainda não podem ser denominadas, a rigor, de operações. Mais adiante, a consciência somente atuará monitorando o desempenho automatizado. Ela consistirá basicamente na "fala interior" construída pelo aluno a partir da interação professor-aluno (oralmente e/ou no material didático) na Zona de Desenvolvimento Proximal ativa nesse contexto educativo. Na ZDP, o professor, presente implicitamente no design das tarefas e explicitamente no tutoramento face a face, prescreve (e fornece andaimes para) ações ao aprendiz nas proximidades do Nível de Desenvolvimento Potencial deste. Tais ações vão sendo automatizadas pelo aluno até que este as realiza satisfatoriamente por si mesmo (Nível de Desenvolvimento Real) - quando então terão passado de ações a operações. Nesse momento, o professor irá retraçar a ZDP para dar lugar a ações mais sofisticadas (novo NDP), que o aluno deverá aos pouco dominar (novo NDR), emergindo novas operações, sem que as anteriores deixem de ser praticadas e consolidadas; e assim por diante.

Leontiev (idem), para reforçar a idéia de automatismo, assinala que, para as operações conscientes se desenvolverem, é típico que elas se formem primeiramente como ações. As operações conscientes são formadas inicialmente como um processo dirigido para o alvo, que só mais tarde adquire a forma, em alguns casos, de hábito automático.

Pinto e Richter (idem, p. 9) apresentam um quadro que sumariza e contextualiza os níveis hierárquicos da atividade a partir da conduta do aluno:

\begin{tabular}{|c|c|}
\hline NÍVEL DA ATIVIDADE & Aprender Português. \\
\hline NÍVEL DAS AÇÕES & $\begin{array}{c}\text { Realizar exercícios, ler textos, produzir textos, compreender } \\
\text { enunciados orais, entre outros. }\end{array}$ \\
\hline $\begin{array}{c}\text { NÍVEL DAS OPERA- } \\
\text { ÇÕES }\end{array}$ & $\begin{array}{c}\text { Como o aluno conduz as ações em termos procedurais a fim } \\
\text { de automatizá-las. }\end{array}$ \\
\hline
\end{tabular}

Tabela 1: Níveis hierárquicos da atividade no universo do livro didático, desenvolvido pelo aluno. 
Na medida em que o aluno vai desenvolvendo determinadas ações para atingir o objetivo de aprender português, ele vai automatizando os procedimentos associados à resolução das tarefas didáticas e, assim, adquirindo conceitos e (micro)habilidades da língua-alvo - componentes estes com que gradativamente constrói sua competência comunicativa. $O$ livro didático de português para estrangeiros serve, então, como uma ferramenta lingüístico-cognitiva para mediar o trabalho do professor e ajudá-lo a gerenciar o espaço da ZDP em que professor e aluno elaboram intersubjetivamente o conhecimento.

\subsection{MODELOS DE LEITURA PRESENTES NO LIVRO DIDÁTICO}

Como já explicitado na metodologia, os exercícios de leitura presentes no LDA estão nas seções Atividades e Leitura Suplementar. Segundo o GP, a seção $A$ tividades, através de exercícios escritos, foi elaborada levando em conta os seguintes objetivos: reutilização do conteúdo funcional (presente na seção Conteúdo Gramatical) e do vocabulário (Expansão Vocabular); retomada da gramática; introdução de novas estruturas; produção e compreensão de textos; informações sobre a cultura popular brasileira. Para este estudo, somente serão mencionadas as atividades de leitura inseridas nessa seção. E, também de acordo com o GP, a seção Leitura Suplementar tem por objetivos abordar assuntos variados da cultura brasileira tais como: músicas, danças, lendas, informações históricas sobre algumas cidades brasileiras, além de apresentar vocabulário relevante.

Algumas dicas de como desenvolver as atividades estão presentes no guia pedagógico do professor. Assim, percebemos que os modelos de leitura, principalmente o descendente (top-down), aparecem algumas vezes como sugestões de trabalho para o professor no GP e não no enunciado da atividade.

A seção Leitura Suplementar da unidade 1 apresenta um texto informativo, intitulado "O Jangadeiro", seguindo de uma foto ilustrativa. No GP, a sugestão de trabalho presente é que o professor pode introduzir superficialmente o assunto (atividade de pré-leitura), fazendo perguntas relacionadas à ilustração, como por exemplo: O que é isso? No seu país há algo parecido? Notamos, então, que o modelo de leitura top-down está presente. As atividades top-down ativam o conhecimento prévio do aluno, o que facilita a compreensão do texto. Outra dica presente no GP, não apenas para esta atividade, mas todas as outras presentes nesta seção, é a utilização de revistas, vídeos etc. para ativar o conhecimento de mundo do aluno a respeito do assunto a ser abordado no texto.

Ainda com respeito a esta unidade, não há exercícios ascendentes (bottomup); o vocabulário relevante do texto é listado com seu significado ao lado. Segundo Carrell (1988), o ensino de vocabulário sem determinar qual é a palavrachave para determinada passagem do texto, sem ensinar conhecimento prévio simultaneamente e sem trabalhar esquemas, geralmente está fadado ao fracasso. A nosso ver, o vocabulário do texto deveria ser trabalhado de acordo com os preceitos de Carrell, pois apresentar listas de palavras novas - até mesmo com definições apropriadas ao seu uso no texto - não garante o aprendizado da palavra ou a compreensão do texto. 
Na unidade seguinte (Leitura Suplementar), outro texto informativo é trabalhado. O título "Festas Religiosas" vem seguido de uma foto ilustrativa do Círio de Nazaré em Belém. No GP, há sugestões de pré-leitura: para introduzir o texto, o professor pode recorrer a figuras ou fotos que representem o assunto abordado. As figuras podem esclarecer o vocabulário contido na leitura, podem adiantar um trabalho que será feito posteriormente, por exemplo: "A festa do Divino está representado por qual figura"? Notamos que tanto o modelo top-down quanto o bottom-up está sendo trabalhado. O primeiro, na introdução do assunto do texto através das figuras, e o segundo, na ênfase ao vocabulário novo também através das figuras. $O$ modelo interativo, então, configura-se nessa atividade de pré-leitura.

A unidade 3, seção de Atividades, traz como texto uma música de Paulinho da Viola - "Sinal Fechado". O aluno deverá ler a música e realizar algumas atividades. Estas atividades são: retirar do texto: a) todas as expressões de saudação; b) todas as expressões de cortesia; c) todos os verbos no presente do indicativo; d) todos os verbos no imperativo. Percebemos que a música serve como pretexto para exercícios ascendentes, fato que condiz com uma abordagem estrutural de ensino de línguas, a qual não trabalha a função dos elementos gramaticais e sim apenas sua forma.

Na seção Leitura Suplementar, um texto informativo intitulado "Belo Horizonte Capital de Minas Gerais", juntamente com duas fotos ilustrativas, é apresentado. No GP, não há sugestões de trabalho de exercícios descendentes e ascendentes. O texto vem acompanhado de um exercício de produção escrita, no qual o aluno deve relatar aspectos de sua cidade natal.

A unidade 4 apresenta exercícios de leitura tanto na seção de Atividades quanto na de Leitura Suplementar. Na primeira seção, uma música de Chico Buarque, "Construção", é trabalhada. Como dica, o GP sugere que o professor faça breves comentários sobre a importância de Chico Buarque de Holanda na Música Popular Brasileira - atividade top-down. O exercício que acompanha a música é de compreensão oral. Na segunda seção, o texto "O Pão de Açúcar" vem acompanhado de uma sugestão no GP: o professor pode usar de todos os recursos disponíveis para motivar esta leitura que, por si só, desperta o interesse por ser um dos pontos turísticos mais conhecidos da cidade do Rio de Janeiro. Dessa forma, o modelo de leitura descendente é enfatizado.

A análise das quatro primeiras unidades do livro didático nos leva a constatar uma tentativa relativamente tímida de se trabalhar com os modelos de leitura. O modelo top-down é o mais recorrente em atividade de pré-leitura, enquanto que 0 ascendente aparece nos poucos exercícios gramaticais presente nas atividades de leitura. Nas unidades 8, 10, 11, 12 e 13, a Leitura Suplementar vem acompanhada de atividades de compreensão do texto, que trabalham tanto o modelo cognitivo top-down quanto o bottom-up, embora superficialmente. Com isso, podemos concluir que os processamentos descendentes, ascendentes e interativo são trabalhados superficialmente. Essa superficialidade é uma falha do livro, já que os modelos de leitura constituem uma importante ferramenta 
para o ensino de línguas em geral e para português para estrangeiros em particular.

\section{CONSIDERAÇÕES FINAIS}

O presente estudo concebe o livro didático de português como gênero, ou mais precisamente, uma ferramenta (no sentido vygotskiano) que medeia o papel do professor e o papel do aluno no espaço intersubjetivo da Zona de Desenvolvimento Proximal (re)traçada no contexto pedagógico. O aluno realiza ações determinadas pelas atividades presentes no LDA, e o professor gerencia essas ações (eventualmente com o apoio do LDP). A atividade em que ambos se inserem está relacionada com o motivo do aluno em se engajar na atividade aprender português (motivo obviamente consensual a profissional e cliente). Para tanto, no livro didático aparecem, entre outras, tarefas de leitura que, ao serem respondidas pelo aprendiz, constituem as ações que este desenvolve na atividade como um todo. Essas ações, se forem satisfatoriamente realizadas, conduzem à automatização de determinado conceito ou (micro)habillidade (supondo, bem entendido, a internalização dos mesmos por meio de emprego contextualizado constante, ver a respeito Richter, 2000).

Os modelos de leitura, como vimos, são primordiais para que o aprendiz consiga construir significado a partir do que o autor propôs. Um dos meios possíveis para que a ação desenvolvida pelo aluno se torne automática é trabalhar, de forma satisfatória, esses modelos de leitura em todas as unidades do livro (ou seja, retomar conceitos e (micro)habilidades ao longo do curso de forma gradativamente mais complexa e sofisticada - o chamado ensino cíclico). Diga-se de passagem, esta é inclusive condição sine qua non para efetivamente se trabalhar ensino-aprendizagem de línguas no espaço de uma ZDP. Como foi constatado no material didático analisado, os modelos de leitura top-down, bottom-up e interativo são enfatizados superficialmente nas atividades de leitura, 0 que compromete o aprendizado e a compreensão do texto como um todo.

Considerando as conclusões acima a respeito do ensino de leitura presente no LDA analisado, podemos sugerir que, para que o aluno aprenda leitura, os meios pelos quais ele realiza suas ações poderiam ser trabalhados a partir de uma aplicação mais incisiva dos modelos de leitura. Assim, conhecimento prévio, conhecimento lingüístico, vocabulário, aspectos formais, esquemas mentais, entre outros, seriam parte fundamental da seção que engloba o ensino de leitura no LDA.

\section{BIBLIOGRAFIA}

CARRELL, P. L. Interactive text processing: implications for ESL/second language reading classrooms. In: CARREL, P. L.; DEVINE, J.; ESKEY, D.E. (eds.). Interactive approaches to second language reading. Cambridge: Cambridge University Press,1988, p. 239-259. 
CARRELL, P. L.; EISTERHOLG, J. C. Schema theory and ESL reading pedagogy. In: CARREL, P. L.; DEVINE, J.; ESKEY, D.E. (eds.). Interactive approaches to second language reading. Cambridge: Cambridge University Press, 1988, p. 73-89.

CARELLI, I. M. Estudar on-line: análise de um curso para professores de inglês na perspectiva da teoria da atividade. Tese de doutorado. Pontifícia Universidade Católica de São Paulo, SP, 2003.

DANIELS, H. Vygotsky e a pedagogia. São Paulo: Loyola, 2003.

ESKEY, D. E.; GRABE, W. Interactive models for second language reading: perspectives on instruction. In: CARREL, P. L.; DEVINE, J.; ESKEY, D.E. (eds.). Interactive approaches to second language reading. Cambridge: Cambridge University Press,1988, p. 223-237.

GOODMAN. K. Unity in reading. In: SINGER H. \& RUDDELL, R. B. Theoretical model and processes of reading. Newark Delaware: Internacional Reading Association, 1985, p.813-840.

. The reading process. In: CARREL, P. L.;DEVINE, J.; ESKEY, D.E.(eds.). Interactive approaches to second language reading. Cambridge: Cambridge University Press,1988, p.11-21.

GRABE, W. Reassessing the term "interactive". In: CARREL, P. L.; DEVINE, J.; ESKEY, D.E. (eds.). Interactive approaches to second language reading. Cambridge: Cambridge University Press,1988, p. 56-70.

GOUGH, P. B. One second of reading. In: KAVANAGH,J.F. \& MATTINGLY, I.G.(orgs). Language by ear and by eye. Cambridge: MIT Press,1972, p.353378).

. One second of reading. In: SINGER H. \& RUDDELL, R. B. Theoretical model and processes of reading. Newark Delaware: Internacional Reading Association,1985, p.661-686.

LEONTIEV, A. N. Activity, consciousnesss, and personality. Englewood Cliffs, Prentice-Hall, 1978.

Dispon. em http://www. marxists.org/archive/leontev/works/1977/leon1977.htm; Acesso em 3 de setembro de 2006.

Uma contribuição à teoria do desenvolvimento infantil. IN

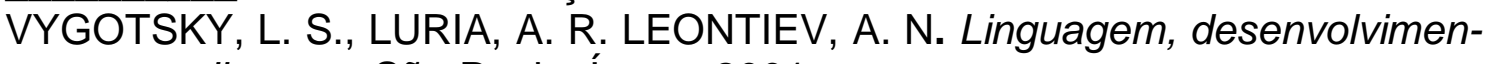
to e aprendizagem. São Paulo: Ícone, 2001.

LIBÂNEO, J. C. A didática e a aprendizagem do pensar e do aprender: a Teoria Histórico-cultural da Atividade e a contribuição de Vasili Davydov.

Disponível em http://www.scielo.br/scielo.php?script=sci arttext\&pid=S141324782004000300002\&lng=e\&nrm=iso; Acesso em 16 de novembro de 2006. 
PAZ, D. M. S. Formação de conceitos de ensino de leitura em português como segunda língua. 2006. 391f. Tese (Doutorado em Letras - Estudos Lingüísticos) - Universidade Federal de Santa Maria, 2006.

PINTO, C. M.; RICHTER, M. G. O livro didático de português para estrangeiros segundo a Teoria da Atividade. In: VI Seminário Internacional em Letras Palavras: Margens e Imagens, 2006, Santa Maria. Anais. Centro Universitário Franciscano, 2006.

RICHTER, M.G. Ensino do português e interatividade. Santa Maria: Ed. UFSM, 2000.

RUMELHART, D. E. Toward an interactive model of reading. In: DORNIC, S. Attention and performance VI. Hillsdale, N.J.: Erlbaum, 1977, p.575-603.

Toward an interactive model of reading. In: SINGER, H; RUDDELL, R. Theoretical models and process of reading. 3ed. Newark, International Reading Association,1985, p.722-751.

SAMUELS, J.; KAMIL, M. Models of the reading process. In: CARREL, P. L.; DEVINE, J.; ESKEY, D.E. (eds.). Interactive approaches to second language reading. Cambridge: Cambridge University Press,1988, p.22-36.

2 Tradução nossa. No original: "Reading is a receptive language process. It is a psycholinguistic process in that it starts with a linguistic surface representation encoded by a writer and ends with meaning which the reader constructs. There is thus an essential interaction between language and thought in reading. The writer encodes thought as language and the reader decodes language to thought".

${ }^{3}$ Tradução nossa. No original: "1. Recognition-initiation. The brain must recognize a graphic display in the visual field as written language and initiate reading. 2. Prediction. The brain is always anticipating and predicting as seeks order and significance in sensory inputs. 3. Confirmation. If the brain predicts, it must also seek to verify its predictions. So it monitors to confirm or disconfirm with subsequent input what it expected. 4. Correction. The brain reprocesses when it finds inconsistencies or its predictions are disconfirmed. 5. Termination. The brain terminates the reading when the reading task is completed, but termination may occur for other reasons: the task is non-productive; little meaning is being constructed, or the meaning is already known, or the story is uninteresting or the reader finds it inappropriate for the particular purpose."

${ }^{4}$ Tradução nossa. No original: "Schema theory shows that the greater the background knowledge a reader has of a text's content area, the better the reader will comprehend that text. The implication of this is that some students' apparent reading problems may be problems of insufficient background knowledge. 
${ }^{5}$ Tradução nossa. No original: "The impact of the information processing approach to studying mental processes is seen within the reading field".

${ }^{6}$ Tradução nossa. No original: "Such instructions can make students aware of how ideas in a text are unified by these cohesive elements".

7 Tradução nossa. No original: "An important part of teaching background knowledge is teaching vocabulary related to it, and, conversely, teaching vocabulary may mean teaching new concepts, new knowledge. Knowledge of vocabulary entails knowledge of the schemata in which a concept participates, knowledge of the networks in which that word participates, as well as any associated words and concepts".

${ }^{8}$ Tradução nossa. No original: "A skilled reader must be able to make use of sensory, syntactic, semantic, and pragmatic information to accomplish his task".

${ }^{9}$ Tradução nossa. No original: "The process of interpretation is guided by the principle that every input is mapped against some existing schema and that all aspects of that schema must be compatible with the input information."

${ }^{10}$ Tradução nossa. No original: "An interactive model of reading assumes that skills at all levels are interactively available to process and interpret the text [...] This model incorporates the implications of reading as an interactive process that is, the use of background knowledge, expectations, context, and so on. At the same time is also incorporates notions of rapid and accurate features recognition for letters and words, spreading activation of lexical forms - that is, a processing that does not depend on context for primary recognition of linguistics units.

${ }^{11}$ Informações retiradas do guia pedagógico do professor. 